\title{
PARTIAL INTERACTION SHEAR FLOW FORCES IN SIMPLY SUPPORTED COMPOSITE STEEL-CONCRETE BEAMS
}

\author{
Y. Zou, X.H. Zhou, J. Di and F.J. Qin* \\ Key Laboratory of New Technology for Construction of Cities in Mountain Area; School of Civil Engineering, \\ Chongqing University, Chongqing, China, 400030 \\ *(Corresponding author: Email: qinfengjiang@cqu.edu.cn)
}

Received: 30 November 2016; Revised: 19 November 2017; Accepted: 19 November 2017

\begin{abstract}
Most existing codes simply limit the shear stress range of stud shear connectors in composite steel-concrete beams to prevent the fatigue failure of studs, and the shear stress range is determined on the basis of a full interaction assumption, which ignores the effects of slip between steel and concrete. However, this hypothesis would overestimate the shear stress range, thereby resulting in the misestimate of the fatigue behaviours of studs. This study herein proposes a method to determine the interface shear flow under either a moving concentrated load or uniform load on the basis of the partial interaction assumption, which considers the effects of slip. Moreover, the interface shear flow, including the shear range and shear peak, under general loading can be predicted using the superposition of moving the concentrated load and uniform load. Furthermore, this method is simplified according to a practically possible range of parameters and is further validated by the finite element method (FEM) model in the case of composite beams with uniformly and non-uniformly distributed shear studs. Finally, a case study is performed using the proposed method and the existing methods to predict the shear stresses and the fatigue life of studs. The results show that the proposed method can provide more accurate and reliable predictions.
\end{abstract}

Keywords: Composite beams, stud shear connector, fatigue, partial interaction, shear flow

DOI: $10.18057 /$ IJASC.2018.14.7

\section{INTRODUCTION}

Since the composite structures, particularly for composite bridges, are subjected to fatigue loading, the fatigue behaviours of steel beams and shear connecters in composite structures have attracted increasing attention among researchers and designers in the past decade [1]. Moreover, stud shear connectors are one of the most common connectors used in composite structures due to their advantages of excellent mechanical properties and construction convenience. However, most of the available literature indicates that fatigue loading could decrease the static strength, increase the plastic slip or even cause the fatigue failure of studs. As a consequence, it is of great significance to investigate the fatigue behaviours of studs in composite structures.

Most studies concerning stud fatigue focus on the relation between the shear stress range and the fatigue life of studs. Based on the experimental data, Johnson [2] proposed a simplified equation to predict the fatigue life of studs using the regression method. Although this equation considers the shear stress range as the only parameter, it has been adopted in Euro code 4 (EC4) $[3,4]$ because of its reliability and simplicity. In 1990, Oehlers [5] investigated the reduction of the static strength of the shear studs due to high-cycle preloading, and this adverse effect is not considered in the existing codes. Moreover, based on the push-out experiments of 71 specimens according to the standard EC4, Hanswille observed the significant plastic slip and shear capacity reduction after high-cycle preloading, and he also argued that the peak load could influence the fatigue behaviours of studs besides the loading range $[6,7]$. Therefore, it is necessary to consider the effects of the peak load on the fatigue behaviour of shear studs, especially in the case of a large peak load. In addition, two full-scale tests of composite beams were conducted and the results verified that fatigue loading 
reduced the interface stiffness and shear capacity of composite beams due to the fatigue behaviours of shear studs [8].

Although the fatigue behaviours of shear studs play a critical role in the performance of composite structures such as composite bridges, the current codes $[3,4,9]$ simply limit the shear stress range based on the full interaction assumption and ignore the effects of the peak load on the fatigue behaviours of shear studs. However, because the partial interaction will significantly affect the interface shear flow force [10-24] and the fatigue behaviours are sensitive to shear force, the fatigue assessment of shear studs would be inaccurate according to the current codes or standards.

Nowadays, various formulations have been developed to determine the stress state of shear studs since it is quite crucial to assess their fatigue behaviours. Seracino [11,12] developed an approach to determine the partial interaction distribution of the interface shear flow of composite beams subjected to a moving concentrated load. Nevertheless, this approach does not take into account the uniform load case, nor analyses the applicability of the approach for composite beams with non-uniformly distributed shear studs. Moreover, it could provide inaccurate results in case of a weak composite action.

According to the linear elastic partial interaction theory, this paper aims to develop a method to determine the distribution of the interface shear flow of the composite beams subjected to the moving concentrated load and/or uniform load. In addition, in the linear elastic analysis, the interface shear flow, including the shear force range and the peak shear, under general loading conditions can be predicted by superposing both the moving concentrated load and the uniform load. Thus, combined with a suitable fatigue formula of studs, the proposed method can be used to more accurately predict the fatigue state of studs under general loading conditions. Furthermore, the proposed method is validated in comparison with the FEM model for cases of composite beams with uniformly and non-uniformly distributed shear studs. Finally, a case study aiming to determine the shear stresses by means of the proposed method and other available methods is given.

\section{LINEAR ELASTIC PARTIAL INTERACTION THEORY}

The method developed herein is based on the linear elastic partial interaction theory originally developed by Newmark et al. [10]. The slip $s$ at the design point $x$ measured from the mid-span is given by the following equation [13]:

$s=K_{1} \sinh (\alpha x)+K_{2} \cosh (\alpha x)+\beta V^{*}$

where $V^{*}$ is the total vertical shear at cross-section $x ; K_{1}$ and $K_{2}$ are the integration constants; the parameters $\alpha$ and $\beta$ govern the behaviour of the composite beam, and they are functions of material and geometric properties of the cross section and the stiffness of the shear connection as follows:

$\alpha=\sqrt{\frac{k}{p E_{s}}\left(\frac{n}{A_{c}}+\frac{1}{A_{s}}+\frac{n d_{c}^{2}}{n I_{s}+I_{c}}\right)}$

and 


$$
\beta=\frac{d_{c} p}{k\left[d_{c}^{2}+\left(I_{s}+\frac{I_{c}}{n}\right)\left(\frac{n}{A_{c}}+\frac{1}{A_{s}}\right)\right]}
$$

where $k$ is the secant stiffness [25]; $p$ is the shear connector spacing; $d_{c}$ is the distance between the centroids of the steel and concrete components; $E$ is the modulus of elasticity; $I$ is the second moment of area; $A$ is the area of cross-section; the subscripts $s$ and $c$ represent the steel and concrete, respectively; $n$ is the modular ratio of $E \mathrm{~s} / E \mathrm{c}$.

The load-slip relationship is

$q_{\mathrm{pi}}=\frac{k s}{p}$

where $q_{\mathrm{pi}}$ is the shear flow fore based on the partial interaction theory, and the subscript $p i$ represents the partial interaction.

\section{DISTRIBUTION OF THE PARTIAL INTERACTION SHEAR FLOW FORCES}

In general, the loading range is dominated by the fluctuations of the live load, while the peak load is the combination of the live load and the dead load. In practice, a uniform load and a moving concentrated load, as shown in Figure 1, can be adopted to represent most of the traffic loadings.

(a) uniform load

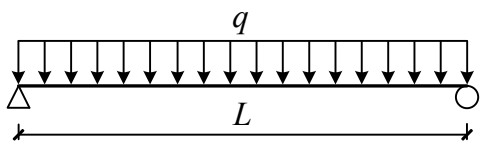

(b) moving concentrated load

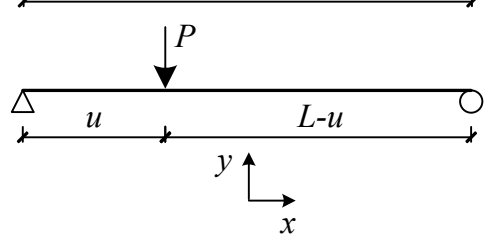

Figure 1. Load Cases

$L$ is the length of the beam; $u$ is the distance from the loading point to the left support of the beam; $q$ is the magnitude of the uniform load; $P$ is the magnitude of the moving concentrated load. The mid-span is assumed as the origin of the coordinates.

\subsection{DISTRIBUTION UNDER THE UNIFORM LOAD}

Under the uniform load, the total vertical shear $V^{*}=-q x$. Substituting it into Eq. 1 gives the distribution of slip:

$s=K_{1} \sinh (\alpha x)+K_{2} \cosh (\alpha x)-\beta q x$

The integration constants $K_{1}$ and $K_{2}$ can be determined using the following two boundary conditions:

$\frac{d s}{d x}=0 \quad x=-L / 2$ 


$$
\frac{d s}{d x}=0 \quad x=L / 2
$$

where $d s / d x=$ slip strain, that is the difference between the axial strain in the steel and the concrete at the interface. Due to the zero longitudinal strain in the steel and the concrete at two supports, the slip strain is equal to zero. Solving the simultaneous equations, the integration constants can be obtained as follows:

$$
\begin{aligned}
& K_{1}=\frac{\beta q L}{\alpha L \cosh (\alpha L / 2)} \\
& K_{2}=0
\end{aligned}
$$

Substituting Eq. 4 into 5, we obtain the distribution of the interface shear flow:

$$
\begin{aligned}
& q_{\mathrm{pi}}= \frac{\beta k q L}{2 p}\left[\frac{2 \sinh (\alpha x)}{\alpha L \cosh (\alpha L / 2)}-\frac{2 x}{L}\right] \\
&=q_{0}\left[\frac{2 \sinh (\alpha x)}{\alpha L \cosh (\alpha L / 2)}-\frac{2 x}{L}\right]
\end{aligned}
$$

Where

$$
q_{0}=\beta k q L / 2 p
$$

The $q_{0}$ is the full interaction interface shear flow force under uniform load at the left support.

As shown in Eq. 10, $\alpha L$ is a parameter considering the material and geometric properties of the beam and the stiffness of the shear connections, and can represent the effects of a partial interaction on the distribution of the interface shear flow. In fact, previous studies [14-16] on composite beams state that the parameter $\alpha L$ governs the partial interaction behaviour of the composite beams with the interlayer slip. When $\alpha L=0$, there is no interaction between steel and concrete; with the increase of $\alpha L$, the interaction between steel and concrete increases; When $\alpha L=\infty$, the composite beam satisfies the hypothesis of full interaction. Additionally, the practical value of $\alpha L$ is normally greater than 5 [26] in common cases; therefore, the parameter $\alpha L$ is adopted to investigate the effects of a partial interaction on the shear flow distribution.

In this part, the proposed method is verified as compared with the FEM model for a simply supported composite beam with a $30 \mathrm{~m}$ span. The details regarding the composite structures including the material and geometric properties are shown in Figure 2(a) and the numerical simulation of the composite beam is conducted using a commercial FEM software (ABAQUS) [27]. As shown in Figure 2(b), the shear connection is modelled by shear springs with a spacing of 150 $\mathrm{mm}$ and the concrete slab and steel beam are modelled by solid and shell elements [24]. The transverse and longitudinal relative displacements between the slab and steel beam are constrained by coupling nodes. The change of parameter $\alpha L$ is achieved by the change in stiffness of the shear springs. 


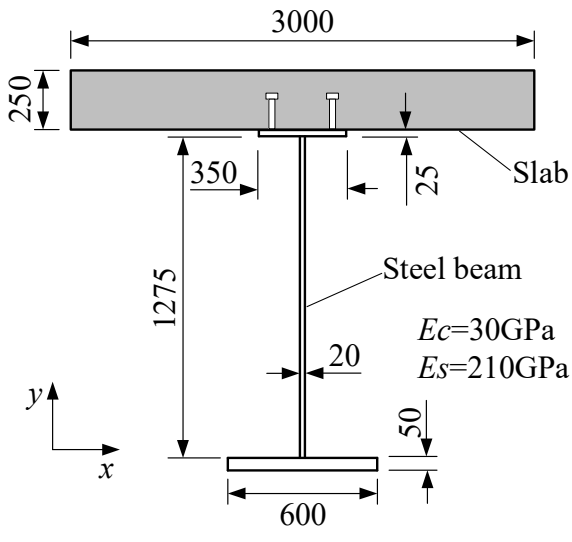

(a)

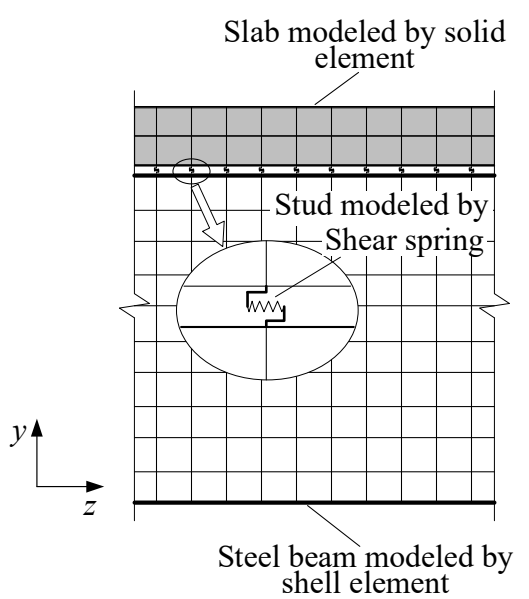

(b)

Figure 2. (a) Cross-section of General Simply Supported Composite Beam ; (b) Modelling of Shear Connectors, Slab and Steel Beam

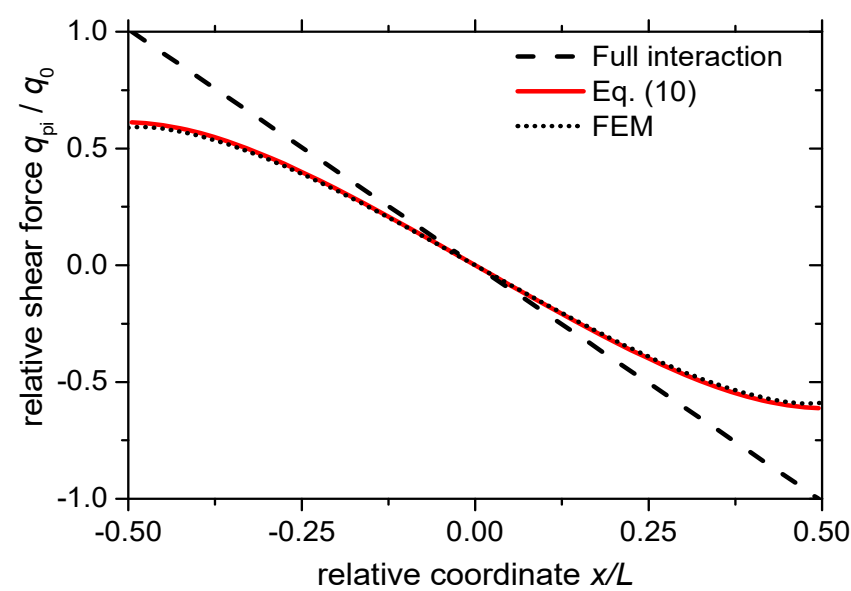

(a)

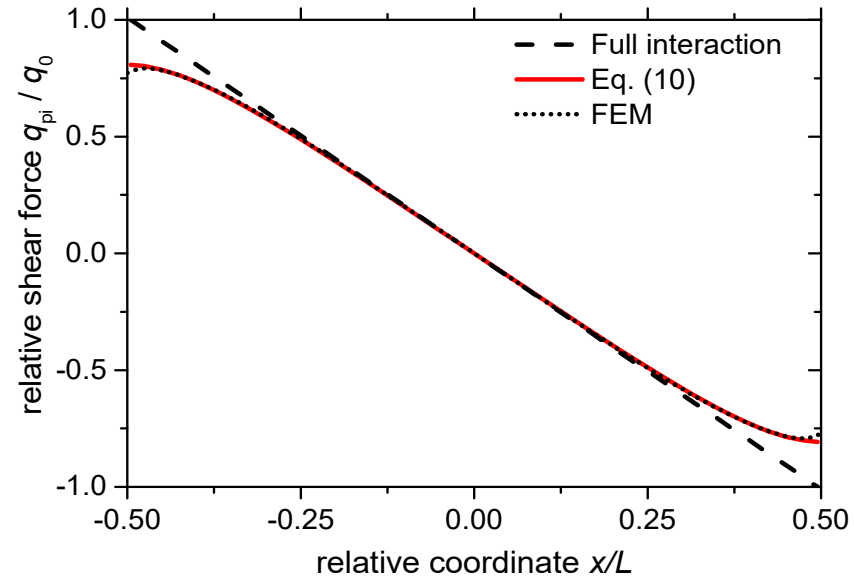

(b) 


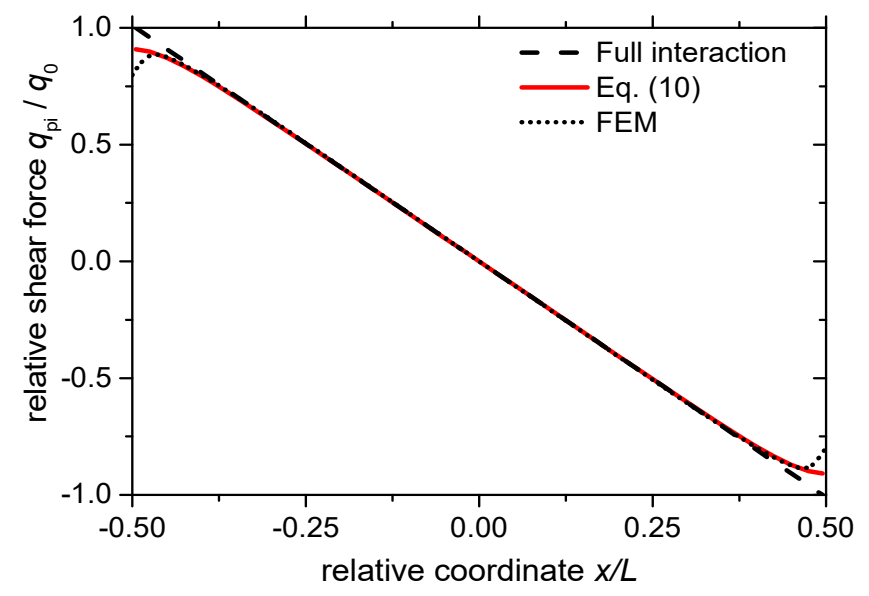

(c)

Figure 3. Distribution of $q_{\mathrm{pi}} / q$ under Uniform Load: (a) $\alpha L=5$; (b) $\alpha L=10$; (c) $\alpha L=20$

As shown in Figure 3, with the decrease of $\alpha L$, the difference between the result of the proposed method and the full interaction method increases. When $\alpha L$ is equal to 5, which implies a relatively weak composite action, the maximum discrepancy reaches about $40 \%$, and thus leads to the use of the full-interaction theory being quite unreliable. In cases of larger values of $\alpha L$, the discrepancies between the results by the proposed method and those by the full-interaction method are also quite obvious. As expected, there is excellent agreement between the proposed method and the numerical simulation.

\subsection{DISTRIBUTION UNDER A MOVING CONCENTRATED LOAD}

Seracino $[11,12]$ proposed a method to determine the reduction in the full interaction shear flow due to a partial interaction. The reduction is defined by the following reduction factor

$R F_{R}=\frac{q_{p i}}{q_{f i}}$

where $q_{p i}$ is the partial interaction interface shear flow force and $q_{f i}$ is the full interaction interface shear flow force. The simplified distribution of $R F_{R}$, shown in Fig.4, is determined by $\left(R F_{R}\right)_{\text {sup }}$, $\left(R F_{R}\right)_{\text {const }}$, and $l_{\text {const. }}$ The simplified expression of $R F_{R}$ at supports is

$$
\left(R F_{R}\right)_{\text {sup }}=1+\frac{1}{\alpha L} \ln \left(\frac{1}{\alpha L}\right)-\frac{2}{(\alpha L)^{2}+1}
$$

The displacement $l_{\text {const }}$ that defines the location where $R F_{R}$ first becomes constant when measured from the supports is

$$
l_{\text {const }}=\frac{-1}{\alpha} \ln \left(\frac{1}{\alpha L}\right)
$$

Finally, the constant magnitude of $R F_{R}$ in the vicinity of the mid-span is

$$
\left(R F_{R}\right)_{\text {const }}=1+\frac{1}{\alpha L}\left\{\ln \left[\frac{2}{(\alpha L)^{2}+1}\right]-1\right\}
$$




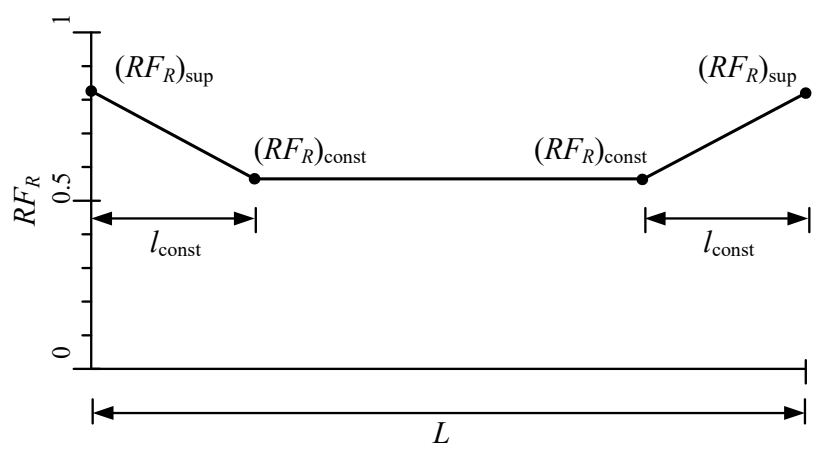

Figure 4. Simplified Shear Flow Range Reduction Factors $R F_{R}{ }^{[11,12]}$

The disadvantage of the method proposed by Seracino is its computational complexity, while the values in the vicinity of the supports require a linear interpolation. In addition, this method is compared with the method proposed herein in the context of accuracy in the following part.

In this part, the method proposed herein is presented in detail. For the composite structures subjected to a moving concentrated load $P$, the shear force distribution is that, on the left side of the load point, $V^{*}=P(L-u) / L$; on the right side of the load point, $V^{*}=-P u / L$. By combining with Eq. 1 , we can obtain the slip distribution as follows:

$$
\begin{array}{ll}
s_{L}=K_{1} \sinh (\alpha x)+K_{2} \cosh (\alpha x)+\beta P \frac{L-u}{L} & (-L / 2 \leq x<u-L / 2) \\
s_{R}=K_{3} \sinh (\alpha x)+K_{4} \cosh (\alpha x)-\beta P \frac{u}{L} \quad(u-L / 2 \leq x \leq L / 2)
\end{array}
$$

where the subscripts $L$ and $R$ represent the left and right shear spans. For the purpose of analysis convenience in the following part, Eqs. 16 and 17 in the exponential form are adopted as follows:

$$
\begin{aligned}
& s_{L}=C_{1} e^{\alpha x}+C_{2} e^{-\alpha x}+\beta P \frac{L-u}{L} \quad(-L / 2 \leq x<u-L / 2) \\
& s_{R}=C_{3} e^{\alpha x}+C_{4} e^{-\alpha x}-\beta P \frac{u}{L} \quad(u-L / 2 \leq x \leq L / 2)
\end{aligned}
$$

The following four boundary conditions are used to determine the integration constants:

$$
\begin{aligned}
& \frac{d s_{L}}{d x}=0 \quad x=-L / 2 \\
& \frac{d s_{R}}{d x}=0 \quad x=L / 2 \\
& s_{L}=s_{R} \quad x=u-L / 2 \\
& \frac{d s_{L}}{d x}=\frac{d s_{R}}{d x} \quad x=u-L / 2
\end{aligned}
$$

Eqs. 20 and 21 represent the boundary conditions at ends, same as the aforementioned Eqs. 6 and 7. Additionally, Eqs. 22 and 23 are obtained according to the continuity conditions of deformation. Solving the simultaneous equations gives the integration constants: 


$$
\begin{aligned}
& C_{1}=\frac{-\beta P}{2} \frac{e^{\alpha L}\left(e^{\alpha(3 L / 2-u)}-e^{\alpha(u-L / 2)}\right)}{e^{2 \alpha L-1}} \\
& C_{2}=\frac{-\beta P}{2} \frac{\left(e^{\alpha(3 L / 2-u)}-e^{\alpha(u-L / 2)}\right)}{e^{2 \alpha L-1}} \\
& C_{3}=\frac{\beta P}{2} \frac{\left(e^{\alpha(L / 2+u)}-e^{\alpha(L / 2-u)}\right)}{e^{2 \alpha L-1}} \\
& C_{4}=\frac{\beta P}{2} \frac{e^{\alpha L}\left(e^{\alpha(L / 2+u)}-e^{\alpha(u-L / 2)}\right)}{e^{2 \alpha L-1}}
\end{aligned}
$$

Substituting Eqs. 24 and 25 into Eq. 18 and 4 gives the distribution of interface shear flow force on the left shear span:

$$
\begin{aligned}
q_{\mathrm{pi}}= & \frac{\beta k P}{p}\left[\frac{L-u}{L}-\frac{e^{2 \alpha u}-e^{2 \alpha L}}{1-e^{2 \alpha L}}\left(\frac{e^{\alpha(L+x)}+e^{-\alpha x}}{2 e^{\alpha(L / 2+u)}}\right)\right] \\
= & q_{0}\left[\frac{L-u}{L}-f(u)\left(\frac{e^{\alpha(L+x)}+e^{-\alpha x}}{2 e^{\alpha(L / 2+u)}}\right)\right]
\end{aligned}
$$

where

$$
\begin{aligned}
& q_{0}=\beta k P / p \\
& f(u)=\frac{e^{2 \alpha u}-e^{2 \alpha L}}{1-e^{2 \alpha L}}
\end{aligned}
$$

The $q_{0}$ is the maximum full interaction interface shear flow force under a moving concentrated load at the left support. As the envelope curve of the interface shear flow is antisymmetric, it is straightforward to determine the minimum of the interface shear flow using the antisymmetric function in Eq. 28. As $q_{\mathrm{pi}}$ is the function of $u$ and $x$, the load position corresponding to the maximum partial interaction positive shear flow at design point $x$ satisfies the following equation:

$$
\frac{d q_{\mathrm{pi}}(x, u)}{d u}=0
$$

However, due to the complexity of Eq. 30, it is quite cumbersome to assess an explicit solution of $u_{\max }$. As the distribution of $f(u)$ illustrated in Figure 5 is close to unity when the value of $\alpha L$ is greater than 5 , it is reasonable to assume that $f(u)=1$.

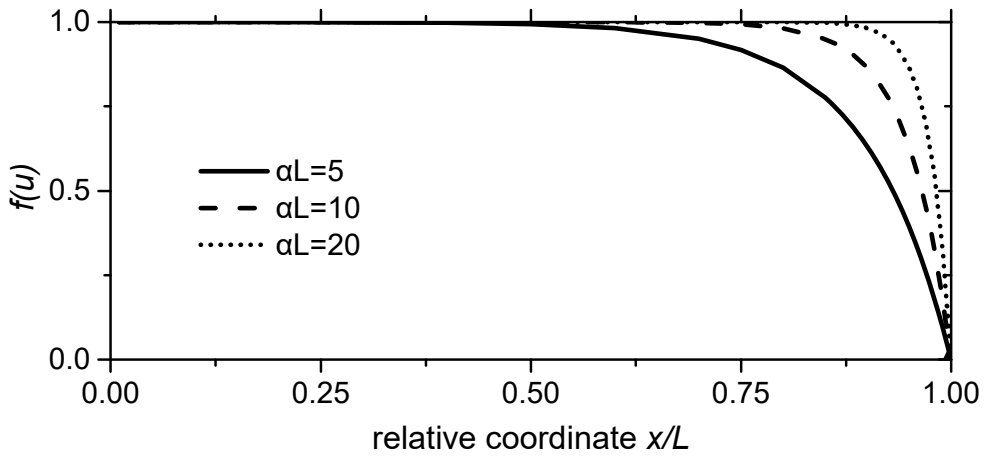

Figure 5. Distribution of $f(u)$ 
Substituting $f(u)=1$ into Eq. 31, and simplifying, gives

$u_{\max }=\frac{1}{\alpha} \ln [\alpha L \cosh (\alpha L / 2+\alpha x)]$

Substituting Eq. 32 into Eq. 28, and simplifying, gives

$q_{\mathrm{pi}, \max }=q_{0}\left\{1-\frac{\ln [\alpha L \cosh (\alpha L / 2+\alpha x)]+1}{\alpha L}\right\}$

Since the maximum interface shear flow is required, let $q_{\text {pi,max }}$ equal to zero when $q_{\text {pi,max }}$ is less than 0 . Since the envelope curve of the interface shear flow is antisymmetric, the minimum of the interface shear flow is given

$q_{\mathrm{pi}, \min }=-q_{0}\left\{1-\frac{\ln [\alpha L \cosh (\alpha L / 2-\alpha x)]-1}{\alpha L}\right\}$

Let $q_{\mathrm{pi}, \min }$ equal to zero when $q_{\mathrm{pi} \text {,min }}$ is greater than 0 . The maximum or minimum shear flow under a moving concentrated load at each design point can be determined using Eqs. 33 and 34, as the red line indicates in Figure 6.

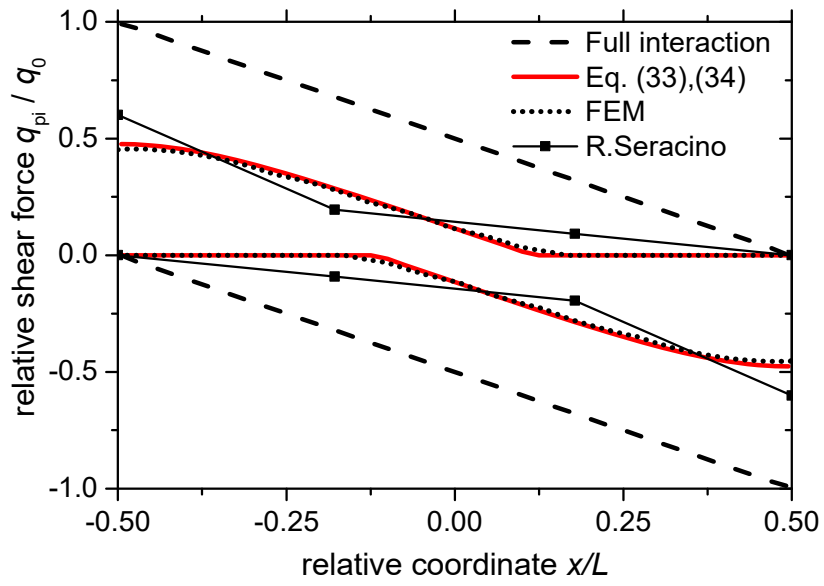

(a)

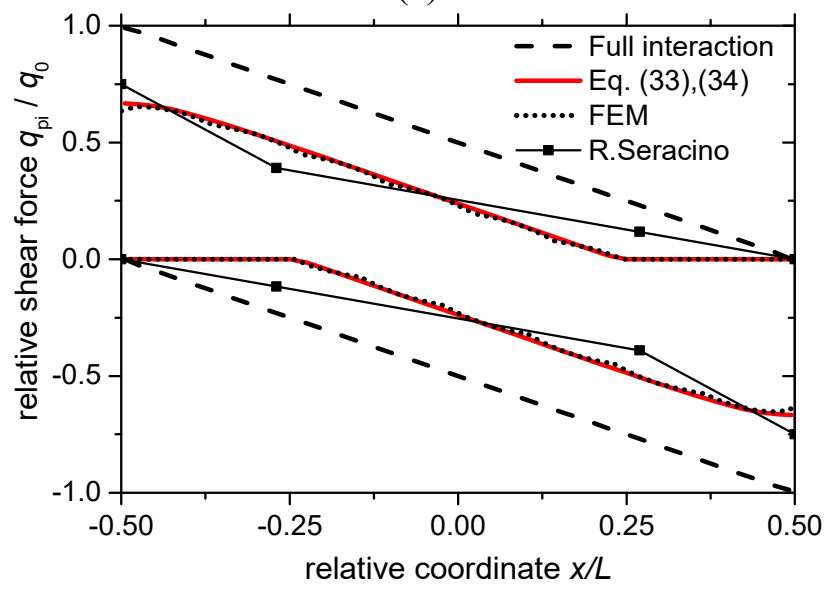

(b) 


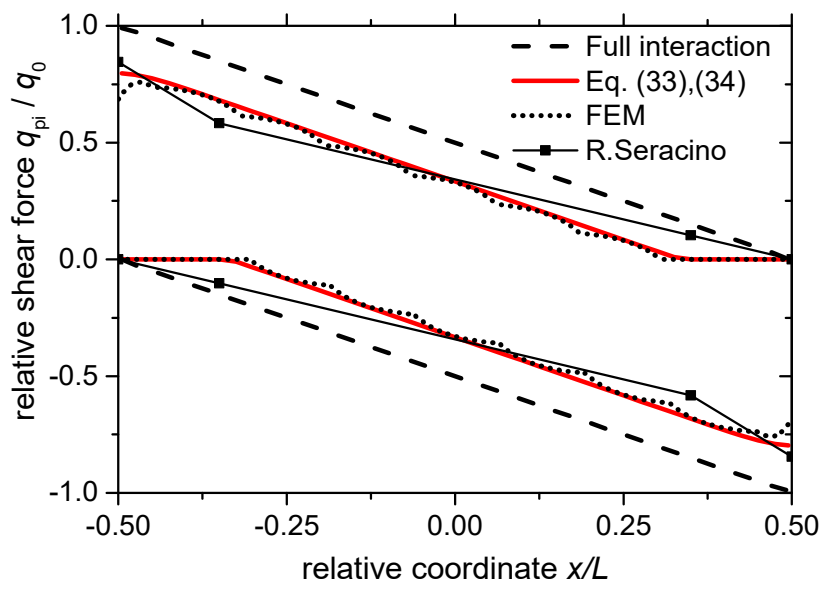

(c)

Figure 6. Envelope Curve of the Interface Shear Flow under a Moving Concentrated Load:

(a) $\alpha L=5$; (b) $\alpha L=10$; (c) $\alpha L=20$

As illustrated in Figure 6, under a moving concentrated load, the reduction of shear flow due to partial interaction reached about $50 \%$ when $\alpha L$ is equal to 5 , and this reduction is more remarkable than that in the uniform loading condition. The proposed method is once again in very good agreement with the numerical simulation and is more accurate than the method proposed by Seracino R $[11,12]$.

\section{ANALYSIS OF APPLICABILITY}

The theoretical derivation of the partial interaction theory is based on the assumption that the distribution of shear studs is uniform. However, the distribution of shear studs is usually non-uniform because of the non-uniform distribution of the interface shear force. It is necessary to validate the proposed approach for the composite beams with non-uniformly distributed shear studs by the FEM model.

Figure 7 shows three cases of composite beams with non-uniformly distributed shear studs, where $L$ is the length of the beam, $p$ is the shear connector spacing, the reference connector spacing $p_{0}$ is $300 \mathrm{~mm}$. The material and geometric properties of the composite beam are shown in Figure 2(a) and the stiffness of each row of studs is $1.063 \times 10^{4} \mathrm{kN} / \mathrm{m}$. In cases 1 and 3, the distribution density of studs on both sides of the beam is about twice that at the mid-span, but the absolute distribution density in case 3 is much larger than that in case 1 . In case 2, distribution density of studs on both sides of the beam is about four times that at the mid-span. As the change of the distribution of studs is reflected in the change of parameter $\alpha L$, the value of $\alpha L$ is also shown in Figure 7. The red solid lines in Figs. 8 and 9 show the distribution of the shear flow determined by the respective values of $\alpha$. 


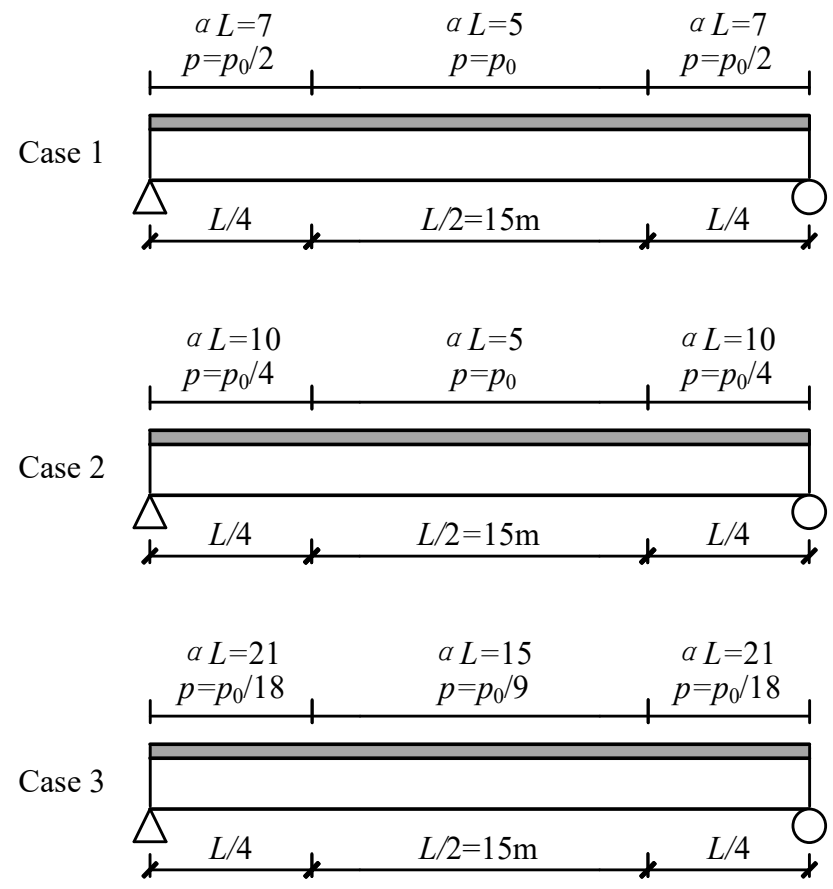

Figure 7. Three Cases of Composite Beams with Non-uniformly Distributed Shear Studs

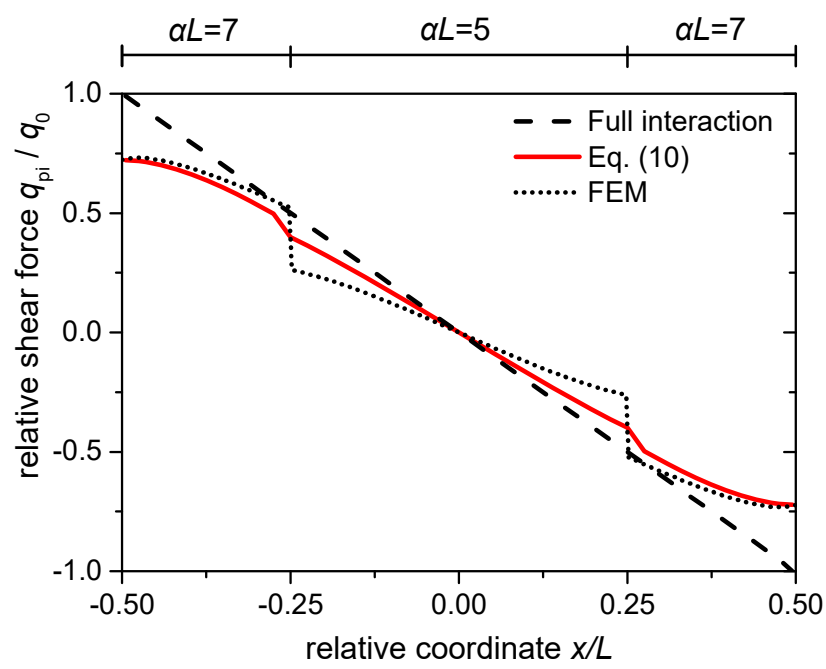

(a) 


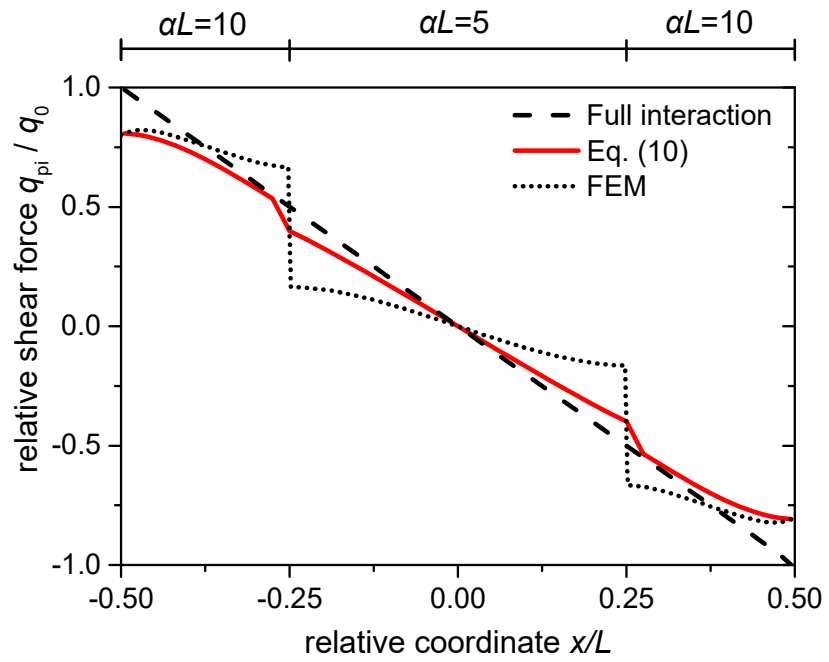

(b)

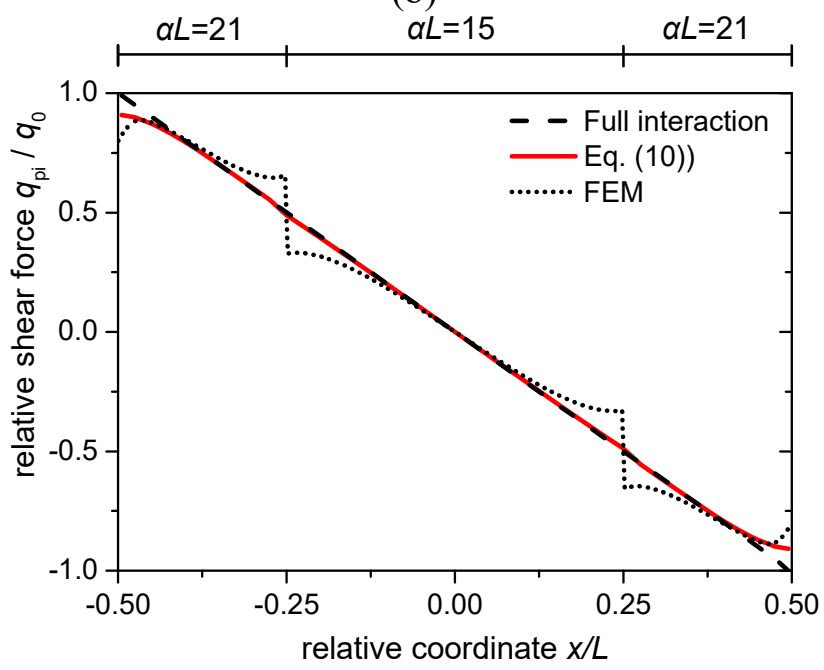

(c)

Figure 8. Distribution of $q_{\mathrm{pi}} / q_{0}$ under Uniform Load: (a) Case 1; (b) Case 2; (c) Case 3

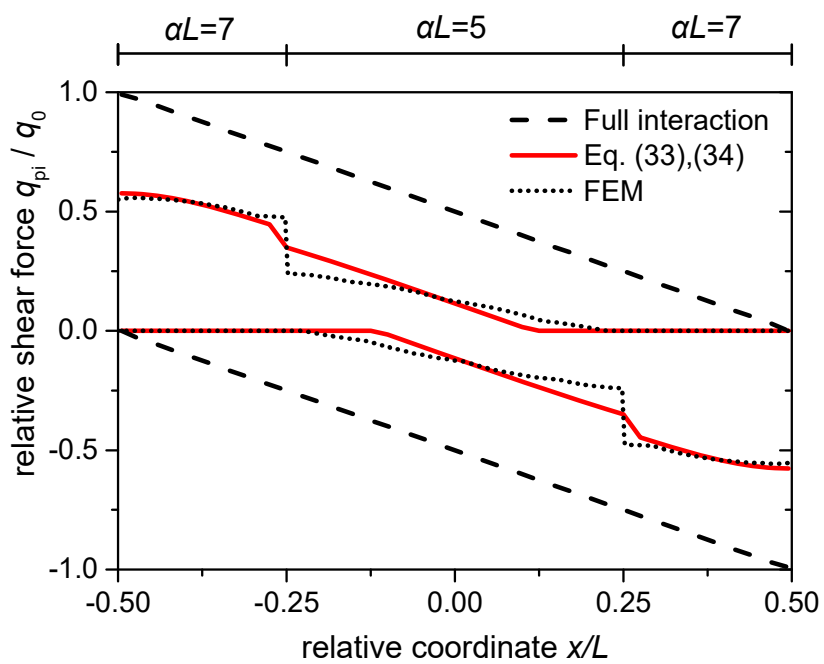

(a) 


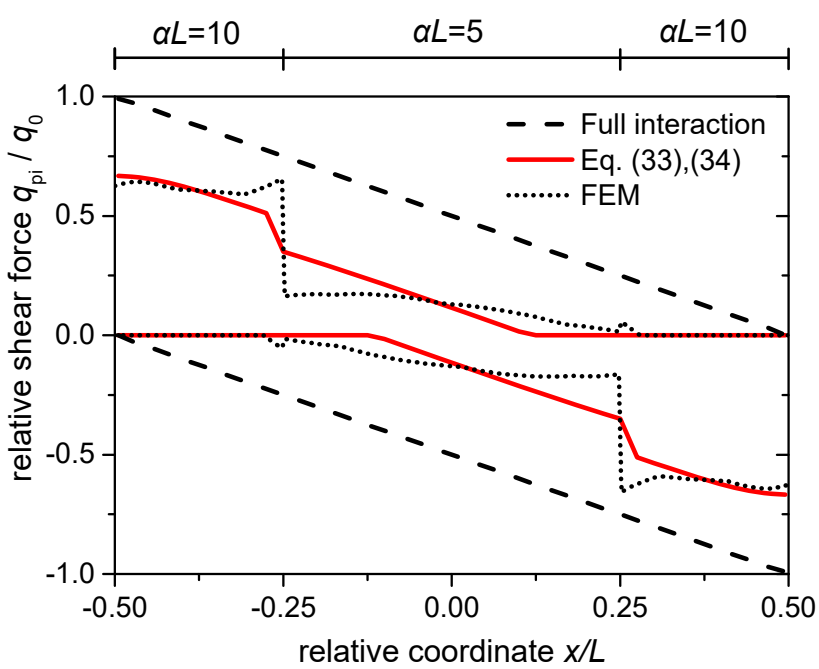

(b)

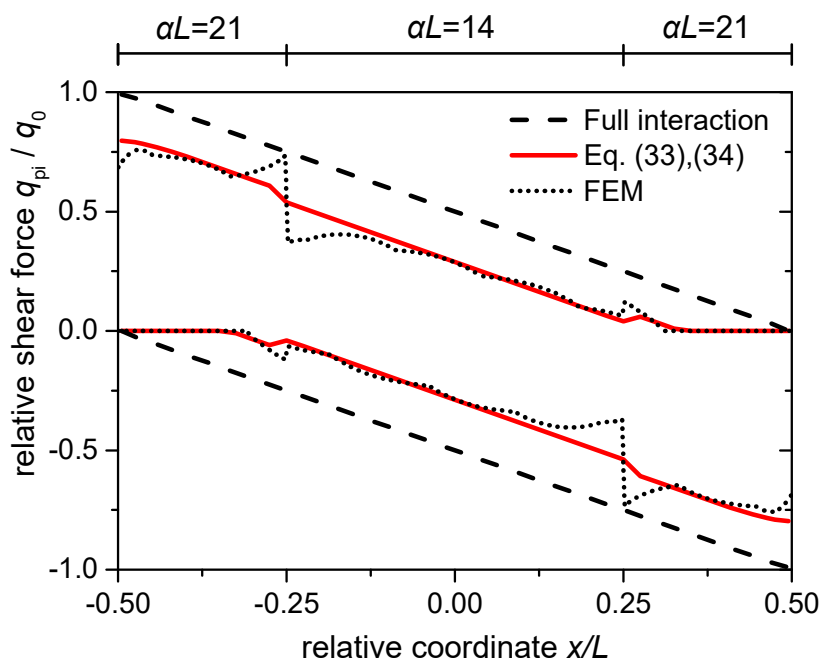

(c)

Figure 9. Distribution of $q_{\mathrm{p}} / q_{0}$ under a Moving Concentrated Load:

(a) Case 1; (b) Case 2; (c) Case 3

When the distribution density of studs on both sides is about four times that at mid-span, as illustrated in Figure 8(b) and 9(b), there are differences between the proposed method and the numerical simulation, especially for the uniform load case. However, the significantly different distribution density of studs is quite rare in practice.

When the distribution density of studs on both sides is about twice that at the mid-span, as illustrated in Figure 8(a) and (c) and Figure 9(a) and (c), with the increase in $\alpha L$, the discrepancies between the proposed method and the numerical simulation also increase. However, limited differences are observed in the local area where $\alpha$ varies, and the proposed method is in good agreement with the numerical simulation on the other locations, especially at the support where the shear force is at a maximum value. This shows that the distribution of shear flows on each part is mainly determined by the respective value of $\alpha$, and the proposed method is also applicable for composite beams with non-uniformly distributed shear studs. 


\section{CASE STUDY}

The following example demonstrates the use of the proposed method in determining the partial interaction force on studs at support and compares the results with those obtained from the full interaction method and from the method developed by Seracino R $[11,12]$. Combined with the fatigue life predicting equation provided by Euro code 4 [3,4] and Hanswille [7], the fatigue life of studs is predicted to illustrate the accuracy and applicability of different methods. The prediction of the reduction of static strength and accumulation of plastic slip due to fatigue loading is not analysed in this paper, but the predicting process is similar to that of fatigue life.

The Euro code $4[3,3]$ specifies that the fatigue life of studs can be calculated as:

$\lg N+8 \lg \Delta \tau=21.935$

where the $\Delta \tau$ is the shear stress range of studs, $N$ is the fatigue life of studs.

Hanswille G [7] suggests that the fatigue life of studs should be calculated as:

$\lg N=\frac{P_{u, 0}-P_{\max }}{0.1267 P_{u, 0}-0.1344 P_{\text {mean }}}$

where $P_{\mathrm{u}, 0}$ is the static strength of studs, $P_{\max }$ is the peak of fatigue loading, $P_{\text {mean }}$ is the mean value of the fatigue loading, and $N$ is the fatigue life of the studs.

Suppose that a $30 \mathrm{~m}$ long simply supported composite beam is subjected to a uniform load of $20 \mathrm{kN} / \mathrm{m}$ as dead load and a moving concentrated load of $320 \mathrm{kN}$ as live load. The material and geometric properties of the composite beam are shown in Figure 2. a. A uniform distribution of connectors was used consisting of two rows of $19 \mathrm{~mm}$ diameter studs with a spacing of $150 \mathrm{~mm}$, giving a static strength of $118.3 \mathrm{kN}$ per stud and connector stiffness of $2.736 \times 10^{4} \mathrm{kN} / \mathrm{m}$ per stud. In this example, the $\alpha L$ is equal to 11.34 according to Eq. 2 . The fatigue shear stress range is given by Eq. 33, because the live load in this example is a moving concentrated load. The shear stress caused by the dead load is given by Eq. 10, because the dead load in this example is a uniform load. The shear stress peak is the sum of the shear stress range and the shear stress caused by dead load. Detailed calculation results are given in Table 1.

Table 1. Comparisons of Shear Stress and Fatigue Life Predicted by Different Methods

\begin{tabular}{ccccc}
\hline \multirow{2}{*}{$\begin{array}{c}\text { Calculating method of } \\
\text { stud force }\end{array}$} & \multirow{2}{*}{$\begin{array}{c}\text { Shear stress } \\
\text { range/MPa }\end{array}$} & \multirow{2}{*}{$\begin{array}{c}\text { Shear stress } \\
\text { peak/MPa }\end{array}$} & \multicolumn{2}{c}{ Fatigue life/106 } \\
\cline { 4 - 5 } code 4 & $\begin{array}{c}\text { Hanswille } \\
\text { curo }\end{array}$ \\
\hline Full interaction & 58.6 & 113.4 & 62.2 & 20.5 \\
Seracino R & 45.1 & - & 503.8 & $\overline{33.2}$ \\
Proposed method & 40.8 & 86.0 & 1117.2 & 33.2 \\
\hline
\end{tabular}

After consideration of the partial interaction effect, as illustrated in Table 1, the calculated shear stress decreased and the predicted fatigue life of studs significantly increased. Compared with the shear stress range predicted by the full interaction theory, the result of the method developed by Seracino $\mathrm{R}$ is reduced by about $23 \%$, and the result of the proposed method is reduced by about $30 \%$. Combined with the fatigue life predicting equation provided by Euro code 4 , fatigue life predicted by the method developed by Seracino $\mathrm{R}$ is about 8 times that of the full interaction theory, and the proposed method predicts about 18 times the fatigue life expectancy of the full interaction 
theory. Compared to the method developed by Seracino R, the proposed method can make full use of the beneficial effect of partial interaction. Combined with the fatigue life predicting equation provided by Hanswille G, fatigue life predicted by proposed method is about $62 \%$ higher than that of the full interaction theory. The method developed by Seracino $\mathrm{R}$ cannot be applied to the equation provided by Hanswille $\mathrm{G}$, because the method does not consider the influence of dead load.

\section{CONCLUSIONS}

A method has been developed to determine the distribution of partial interaction interface shear flows of composite beams subjected to a moving concentrated load and uniform load. This method is validated by the finite element model (FEM) of the composite beam with uniformly and non-uniformly distributed shear studs. Also, an example of predicting shear stresses and the fatigue life of studs in composite beams with different methods is given. The main conclusions from the study are as follows:

(1) Under the uniform load, the reduction of shear flow due to partial interaction can reached about $40 \%$ when the composite action is relatively weak. The proposed method is in excellent agreement with the numerical simulation.

(2) Under a moving concentrated load, the reduction of shear flow due to partial interaction reach about $50 \%$ when the composite action is relatively weak. Since the proposed method is reasonably simplified according to a practically possible range of $\alpha L$, it is in better agreement with the numerical simulation than the existing methods. When used with an appropriate fatigue model, this method can be used to more accurately assess the fatigue behaviour of studs.

(3) When the proposed method is applied to composite beams with uniformly or non-uniformly distributed shear studs, the discrepancies between the proposed method and numerical simulation are obvious only in the local area where the change of stiffness is drastic. On the other positions, especially at supports where the shear force is maximum, the proposed method is in good agreement with the numerical simulation.

(4) The interface shear flows, including shear range and peak shear, can be predicted using the superposition of the moving concentrated load and uniform load, and therefore the method can be applied to more general loading conditions. When used with an appropriate fatigue model, this method can provide an accurate and reliable assessment of the fatigue behaviours of shear studs.

\section{ACKNOWLEDGMENT}

The authors express their sincere gratitude for the financial support provided by the National Key R\&D Program of China (2016YFC0701202), Science and technology R\&D Project of China Communications Construction Co (2014-ZJKJ-PTJC03), the Traffic Science and Technology Projects of the Ministry of Transport (2013318798320), and the National Natural Science Foundation of China (51608069). 


\section{REFERENCES}

[1] Wang, Y.H., Nie, J.G. and Li, J.J., "Study on Fatigue Property of Steel-concrete Composite Beams and Studs", Journal of Constructional Steel Research, 2014, Vol. 94, No. 94, pp. $1-10$.

[2] Johnson, R.P., "Shear Connection for Composite Bridges and Eurocode 4: Part 2", Proceedings of Composite Construction-Conventional and Innovative, International Conference, Innsbruck, Austria, 1997, pp. 573-578.

[3] EN 1994-1-1, "Eurocode 4: Design of Composite Steel and Concrete Structures. Part 1-1: General Rules and Rules for Buildings", European Committee for Standardization, 2004.

[4] EN 1994-2, "Eurocode 4: Design of Composite Steel and Concrete Structures. Part 2: General Rules and Rules for Bridges", European Committee for Standardization, 2004.

[5] Oehlers, D.J., "Deterioration in Strength of Stud Connectors in Composite Bridge Beams", Journal of Structural Engineering, 1990, Vol. 116, No. 12, pp. 3417-31.

[6] Hanswille, G., Porsch, M. and Ustundag, C., "Resistance of Headed Studs Subjected to Fatigue Loading, Part I: Experimental Study", Journal of Constructional Steel Research, 2007, Vol. 63, No. 4, pp. 475-484.

[7] Hanswille, G., Porsch, M. and Ustundag, C., "Resistance of Headed Studs Subjected to Fatigue Loading, Part II: Analytical Study", Journal of Constructional Steel Research, 2007, Vol. 63, No. 4, pp. 485-493.

[8] Hanswille, G. and Porsch, M., "Lifetime Oriented Design Concepts of Steel-Concrete Composite Structures Subjected to Fatigue Loading", Proceedings of Composite Construction in Steel and Concrete VI, ASCE, 2011, pp. 14-25.

[9] AASHTO LRFD, "Bridge Design Specifications", 3rd Ed. American Association of State Highway and Transportation Officials, 2004.

[10] Newmark, N.M., "Test and Analysis of Composite Beams with Incomplete Interaction", Proc. Society for Experimental Stress Analysis, New York,1951, Vol. 9, No. 1, pp. 75-92.

[11] Seracino, R., Oehlers, D.J. and Yeo, M.F., "Partial-interaction Fatigue Assessment of Stud Shear Connectors in Composite Bridge Beams", Structural Engineering and Mechanics, 2002, Vol. 13, No. 4, pp. 455-464.

[12] Seracino, R., Lee, C.T. and Tan, Z., "Partial Interaction Shear Flow Forces in Continuous Composite Steel-concrete Beams", Journal of Structural Engineering, ASCE, 2006, Vol. 132, No. 2, pp. 227-236

[13] Johnson, R.P., "Composite Structures of Steel and Concrete, Vol. 1: Beams, columns, frames and applications in buildings", 3rd Ed. Oxford: Blackwell Scientific, 2004.

[14] Girhammar, U.A. and Gopu, V.K.A., "Composite Beam-Columns with Interlayer Slip_Exact Analysis”, Journal of Structural Engineering, ASCE, 1993, Vol. 119, No. 4, pp. $1265-1282$.

[15] Girhammar, U.A. and Pan, D. H., "Exact Static Analysis of Partially Composite Beams and Beam-columns", International Journal of Mechanical Sciences, 2007, Vol. 49, No. 2, pp. 239-255.

[16] Girhammar, U.A., "A Simplified Analysis Method for Composite Beams with Interlayer Slip", International Journal of Mechanical Sciences, 2009, Vol. 51, No. 7, pp. 515-530.

[17] Ranzi, G., Bradford, M.A. and Uy, B., "A General Method of Analysis of Composite Beams with Partial Interaction”, Steel \& Composite Structures, 2003, Vol. 3, No. 3, pp. 169-184.

[18] Zanuy, C., "Analytical Equations for Interfacial Stresses of Composite Beams due to Shrinkage", International Journal of Steel Structures, 2015, Vol. 15, No. 4, pp. 999-1010.

[19] Hwang, J.W. and Kwak, H.G., "Improved FE Model to Simulate Interfacial Bond-slip Behavior in Composite Beams under Cyclic Loadings", Computers \& Structures, 2013, Vol. 125, No. 1, pp. 164-176. 
[20] Gara, F., Ranzi, G. and Leoni, G., "Partial Interaction Analysis with Shear-lag Effects of Composite Bridges: A Finite Element Implementation for Design Applications", Advanced Steel Construction, 2011, Vol. 7, No. 1, pp. 1-16.

[21] Mirza, O. and Uy, B., "Effects of Strain Regimes on the Behaviour of Headed Stud Shear Connectors for Composite Steel-concrete Beams", Advanced Steel Construction, 2010, Vol. 6, No. 1, pp. 635-661.

[22] Lin, W.W. and Yoda, T., "Experimental and Numerical Study on Mechanical Behavior of Composite Girders under Hogging Moment", Advanced Steel Construction, 2013, Vol. 9, No. 4, pp. 309-333.

[23] Aleksandar, P., Besevic. M.T. and Vojnic-Purcar, M., "A Numerical Method for Free Vibration of Axially Loaded Composite Timoshenko Beam”, Advanced Steel Construction, 2016, Vol. 12, No. 1, pp. 55-65.

[24] Queiroz, F.D., Vellasco, P. and Nethercot, D.A., "Finite Element Modelling of Composite Beams with Full and Partial Shear Connection”, Journal of Constructional Steel Research, 2007, Vol. 63, No. 4, pp. 505-521.

[25] Wang, Y.C., "Deflection of Steel-concrete Composite Beams with Partial Shear Interaction", Journal of Structural Engineering, ASCE, 1998, Vol. 124, No. 10, pp. 1159-65.

[26] Nie, J., Shen, J. and Yu, Z., "A Reduced Rigidity Method for Calculating Deformation of Composite Steel-concrete Beams”, China Civil Engineering Journal, 1995, Vol. 28, No. 6, pp. 11-17. (in Chinese)

[27] ABAQUS Documentation, Version 6.10, Dassault System, USA, 2010. 